\title{
A FORMAÇÃO PROFISSIONAL, INTERDISCIPLINARIDADE E SEU PROCESSO DE AQUISIÇÃO
}

\author{
Richarla Fortunato de Oliveira ${ }^{1}$ \\ Sonia Tebet Mesquita ${ }^{2}$ \\ Cleonice da Silva ${ }^{3}$
}

\section{RESUMO}

O Centro de Pesquisa Audiológicas (CPA) é uma unidade do Hospital de Reabilitação de Anomalias Craniofaciais (HRAC) da Universidade de São Paulo (USP), que atende a portadores de deficiência auditiva, estando seu trabalho voltado para ensino, pesquisa e prestação de serviço. Desenvolve programas que exigem a atuação de uma equipe interdisciplinar e em todas essas áreas, existem profissionais em nível de especialização que estão em formação/treinamento profissional. Em virtude do atendimento ser interdisciplinar no CPA, de acordo com os princípios do HRAC, verificou-se a necessidade de investigar o conhecimento que esses profissionais possuem sobre o tema: a interdisciplinaridade. $\mathrm{O}$ universo da pesquisa foi constituído por 13 profissionais (100.0\%) das diferentes áreas, representados por 09 sujeitos (69.2\%) e teve como objetivo constatar o nível do conhecimento dos alunos/especializandos e sua consciência sobre a interdisciplinaridade no cotidiano do CPA. A pesquisa foi exploratória, valendo-se da abordagem quanti-qualitativa, tendo como instrumental técnico, o questionário com perguntas abertas. Constatamos que os profissionais reconheceram o trabalho no cotidiano do CPA como interdisciplinar e que, apesar de terem tomado conhecimento do tema interdisciplinaridade - durante a graduação (88.9\%), a vivência interdisciplinar só se efetivou durante seu treinamento profissional.

PALAVRAS-CHAVE: Equipe Interdisciplinar de Saúde, Serviço Social.

\footnotetext{
${ }^{1}$ Especializanda em Serviço Social na área de saúde e reabilitação pelo Hospital de Reabilitação de Anomalias Craniofaciais da Universidade de São Paulo (HRAC /USP), Bauru-SP.

${ }^{2}$ Mestre em Serviço Social e Assistente Social do HRAC/ USP, Bauru-SP.

${ }^{3}$ Especialista em Serviço Social na área de saúde e reabilitação pelo HRAC/ USP e Assistente Social do HRAC/ USP, Bauru-SP.

\begin{tabular}{llllll}
\hline Serviço Social \& Saúde & Campinas & v. 4 & n. 4 & p. 1-156 & Maio 2005 \\
\hline
\end{tabular}
}




\section{INTRODUÇÃO}

O Hospital de Reabilitação e Anomalias Craniofaciais (HRAC/USP) é um hospital especializado no atendimento de portadores de malformações e distúrbios da audição, linguagem e visão. Desenvolve atividades ligadas às áreas de ensino, pesquisa e prestação de serviços, voltados para a (re)habilitação desses sujeitos, com o objetivo de definir e aprimorar técnicas de diagnóstico, prevenção e atendimento ao portador de deficiência auditiva. Em 1996, o HRAC/USP, por meio da área de ensino, implantou o curso de pós-graduação e, desde então, tem oferecido cursos de especialização "latu sensu" em audiologia, dentística, endodontia, implantodontia, osseointegrada, odontopediatria, ortodontia, prótese dentária, psicologia clínica, radiologia odontológica em saúde coletiva, nutrição clínica e serviço social (GARCIA, 2001).

Além das aulas teóricas, o curso desenvolve um programa de treinamento que proporciona aos profissionais/ especializandos a oportunidade de atuar em diferentes programas do HRAC/ USP, desenvolvidos em suas unidades.

O Centro de Pesquisas Audiológicas (CPA) é uma unidade do HRAC/ USP, criada em 1990, que atende a portadores de deficiência auditiva e desenvolve programas em nível de diagnóstico diferencial, prevenção, habilitação e reabilitação (de portadores de deficiência auditiva) de abrangência nacional e internacional, e, dentre eles, destaca-se o Programa de Implante Coclear. Estes programas envolvem a atuação de uma equipe interdisciplinar que conta com profissionais em nível de especialização que estão em formação/treinamento profissional, sendo o trabalho do CPA classificado como interdisciplinar, nos mesmos moldes do HRAC/USP.

A interdisciplinaridade pode ser entendida como um trabalho em comum, onde se consideram a interação das disciplinas científicas, de conceitos, diretrizes, de sua metodologia e de seus procedimentos.

É a interação desses saberes que tem possibilitado uma visão holística do paciente para compreensão de sua realidade, que vai além da sua condição de portador de deficiência e sua necessidade/direito de reabilitação implica em visualizar sua situação global, de pertencer a vários níveis, que fazem dele - paciente, um ser humano pluridimensional - um cidadão com direito ao atendimento oferecido pelo CPA.

\begin{tabular}{llllll}
\hline Serviço Social \& Saúde & Campinas & v. 4 & n. 4 & p. 1-156 & Maio 2005 \\
\hline
\end{tabular}


Essas considerações sugerem uma reflexão a respeito de como a interdisciplinaridade foi apreendida e vivenciada pelos membros dessa equipe. Neste caso, os alunos especilizandos/ residentes que atuaram no CPA.

Segundo SEVERINO (1989), a interdisciplinaridade implica no plano práticooperacional em que se estabelece mecanismos e estratégias de efetivação desse diálogo solidário no trabalho científico, tanto na prática da pesquisa como naquela do ensino e da prestação de serviços.

A interdisciplinaridade é fundamentada num regime de co-propriedade, possibilitando o diálogo entre as diversas disciplinas, o que leva a uma interação ou uma intersubjetividade - condição para efetivação do trabalho interdisciplinar.

Portanto, este trabalho teve como objetivo geral: constatar o nível do conhecimento dos alunos especializandos/residentes sobre a interdisciplinaridade e sua consciência sobre a interdisciplinaridade no cotidiano do CPA.

O estudo apresentará algumas considerações sobre a rotina interdisciplinar no CPA e abordará aspectos da formação profissional e interdisciplinar, na fala de vários autores, precedendo a análise dos resultados obtidos com a pesquisa.

\section{A INTERDISCIPLINARIDADE NO COTIDIANO DO CENTRO DE PESQUISAS AUDIOLÓGICAS}

A interdisciplinaridade no CPA acontece em sua rotina diária de atendimento, por meio de uma equipe interdisciplinar básica formada por:

- Assistentes Sociais; Médicos (Otorrinolaringologistas); Fonoaudiólogas; Psicólogas; e, outros profissionais do Hospital, quando necessário.

No atendimento de caso novo (primeiro atendimento no CPA), o paciente passa por uma rotina que começa com uma abordagem grupal - reunião de caso novo coordenada pela Assistente Social. Ao seu término, iniciam-se os atendimentos individuais:

- avaliação social (estudo social, encaminhamentos e providências);

- avaliação fonoaudiológica (exames e teste);

- avaliação otorrinolaringológica;

- avaliação psicológica;

\begin{tabular}{llllll}
\hline Serviço Social \& Saúde & Campinas & v. 4 & n. 4 & p. 1-156 & Maio 2005
\end{tabular} 
- avaliação com profissionais de outras áreas, de acordo com a necessidade (pediatra, neurologista, clínico geral, geneticista, endocrinologista, oftalmologista e outros).

Nos retornos, o paciente passa por todos os profissionais para dar continuidade aos procedimentos iniciados pela equipe. Todos os atendimentos são registrados em um prontuário único que facilita/possibilita a visão interdisciplinar do paciente.

Periodicamente, acontecem reuniões com a equipe interdisciplinar para discussão dos casos e, posteriormente, a definição de conduta. Mais uma vez, a interdisciplinaridade se apresenta e, com o parecer de cada profissional - de acordo com atendimentos anteriores - o paciente é avaliado e compreendido em suas dimensões.

\section{FORMAÇÃO PROFISSIONAL E INTERDISCIPLINARIDADE: ASPECTOS NORTEADORES}

Dentre os vários autores que tem estudado a interdisciplinaridade e a formação profissional, foram selecionados alguns que nos darão subsídios para análise dos resultados.

Atualmente, o ensino superior é composto por duas naturezas distintas de universidades: a Universidade de Consumo, configurando a grande maioria das escolas que se dedicam exclusivamente ao ensino como regra, em nível de graduação e, excepcionalmente, ministram cursos de extensão e aperfeiçoamento e a Universidade da Produção, constituída por Centros de Excelência - a exemplo do HRAC/USP - que tem a tarefa e o privilégio de desenvolver pesquisas e ministrar cursos de pós-graduação (CARRARA, 2001).

Para tanto, uma instituição de ensino bem estruturada, segundo esse autor, deve ter a capacidade de articular fontes externas em âmbitos político, econômico e cultural, identificando as necessidades manifestas pela sociedade. Percebemos hoje que uma das demandas é a mediação entre as disciplinas, isto é, trabalho em equipe. ${ }^{4}$

\footnotetext{
4 "Pessoas motivadas, com uma disposição cultural para trabalharem juntas com visão e paciência para traçar uma estratégia e colocá-la em prática" ( ROBBINS, H., FINLEY, M. Por que as equipes não funcionam: o que não deu certo e como torná-las criativas e eficientes. Rio de Janeiro: Campus, 1997 p.7 ). \begin{tabular}{llllll}
\hline Serviço Social \& Saúde & Campinas & v. 4 & n. 4 & p. 1-156 & Maio 2005
\end{tabular}
} 
Cabe, ainda, a cada Instituição de Ensino, o compromisso de formar profissionais que sejam capazes de trabalhar numa visão de totalidade, sem anular seu saber individual diante do saber coletivo. Esta é a principal característica do trabalho interdisciplinar que, de acordo com RODRIGUES ON (1998), não fere a especificidade das profissões e tampouco seus campos de especialidade, mas requer originalidade e diversidade dos conhecimentos. Na prática, a interdisciplinaridade cria estratégias enriquecedoras para a ação profissional, produzindo uma competência que dificilmente o indivíduo sozinho teria. Vale ressaltar que nem todos os profissionais possuem a mesma perspectiva de trabalho, isto porque tiveram uma formação com metodologias de ensino diferentes.

Desta forma, acredita-se que a universidade possui um papel de extrema importância, ou seja, o de formar profissionais comprometidos com seu trabalho, priorizando a qualidade do mesmo, tendo a consciência de que, para desenvolvê-lo com êxito, é necessária a participação de uma equipe competente e disposta a caminhar junta.

O indivíduo não nasce competente, torna-se. Isso ocorre por meio da busca do saber, conhecendo novas teorias, técnicas e as colocando em prática com comprometimento e responsabilidade junto ao trabalho.

Para tanto, o profissional deve ter uma formação preocupada com a qualidade dos serviços prestados, procurando conhecer para argumentar sua prática, usando as técnicas, não como um instrumento abstrato e sim um instrumento real para o desenvolvimento de sua ação (ANDRAUS, 1996), no compartilhamento com outras disciplinas.

A questão do saber está diretamente relacionada ao nosso cotidiano, que nos leva a buscar novos conhecimentos e a repensar nossas atitudes como profissionais. "O saber, enquanto expressão da prática simbolizadora dos homens, só será autenticamente saber quando se der interdisciplinarmente” (SEVERINO, 1989, p.53).

Para ANDRAUS (1996), ser interdisciplinar para o saber e para ação é um movimento de renovação, onde mais do que teorias é preciso aprimorar atitudes no sentido de reconhecer que a pluralidade nos coloca múltiplas possibilidades de desvelar o real, repensar a prática e transformá-la. É ter em mente que não se é totalmente dono do saber, buscando uma integração entre os demais participantes da equipe, visando crescimento

\begin{tabular}{llllll}
\hline Serviço Social \& Saúde & Campinas & v. 4 & n. 4 & p. 1-156 & Maio 2005 \\
\hline
\end{tabular}


profissional e pessoal, vindo a acrescentar e não fragmentar o trabalho a ser desempenhado. Todos precisam despir-se de seus pré-conceitos e estarem aptos a receber críticas, visualizando como algo que virá contribuir para o seu crescimento, o bom andamento da equipe e, conseqüentemente, sucesso nas atividades realizadas (ANDRAUS, 1996). A autora afirma, ainda, que, para ocorrer a interdisciplinaridade, o profissional precisa ser interdisciplinar, buscando a integração com o conjunto, pois a interdisciplinaridade decorre do encontro entre os indivíduos e não das disciplinas propriamente ditas; a união do grupo e o entusiasmo, suscita o desejo de participação.

DEMO (1997), coloca que o trabalho em equipe é a verdadeira interdisciplinaridade, na qual os conhecimentos sempre especializados buscam a convergência e, possivelmente, a constituição de uma atividade única, realizada por muitas mãos. Ressalta que nem todo grupo pode ser tomado como interdisciplinar, pois não é o grande número de pessoas no conjunto que traz a interdisciplinaridade, mas sua formação diversificada.

Tendo em vista que a formação da equipe se faz em torno de um sujeito ou objetivo, a interdisciplinaridade deve ser compreendida como a interlocução de várias disciplinas, com o mesmo objetivo, onde cada uma delas desenvolve seu trabalho de forma competente, para que todos possam contribuir, garantindo bons resultados dos trabalhos desempenhados pela equipe e a satisfação daqueles que dele necessita.

Para se atuar em uma perspectiva interdisciplinar é importante ter consciência de que não se está só no mundo. No trabalho em equipe há a necessidade da convivência entre os profissionais, no compartilhamento das decisões - cada membro tem sua função que, se agrupada, resulta num trabalho eficiente e satisfatório a todos.

Interdisciplinaridade, de acordo com RODRIGUES ON (1998, p.156), pode ser classificada como uma "técnica didática, um instrumento utilitário, um princípio de homogeneização ou um modelo metodológico capaz de produzir idéias generalizadoras ou universalizantes ". Consiste num trabalho em comum, em que se consideram a mediação das disciplinas científicas, de seus conceitos, diretrizes e de seus procedimentos. É uma ação que se exerce coletivamente, buscando alternativas para determinados questionamentos, sendo sua marca principal é a responsabilidade individual.

\begin{tabular}{llllll}
\hline Serviço Social \& Saúde & Campinas & v. 4 & n. 4 & p. 1-156 & Maio 2005
\end{tabular} 
O trabalho interdisciplinar implica responsabilidade, respeito aos colegas e suas atitudes. Não é apenas uma metodologia, mas uma filosofia de vida, pois o profissional realiza seu trabalho voltado para o grupo, buscando aprimoramento e novas formas de desenvolver suas atividades, de forma que a equipe cresça, principalmente na qualidade dos serviços oferecidos. A equipe pode ser exemplificada como um corpo onde os membros devem funcionar integrados, para o bom andamento do todo.

Para o trabalho interdisciplinar é necessário uma relação de reciprocidade, de mutualidade, que pressupõe uma atitude diferente a ser assumida frente ao problema de conhecimento, isto é, substituir a concepção fragmentária pela unitária do ser humano” (SAMPAIO et al., 1989, p. 82).

“Em suma, ser interdisciplinar, hoje, requer uma atitude política e pedagógica que demanda coragem, despojamento e muita dedicação” (FAZENDA, 2001, p. 74), não perdendo de vista o sujeito da ação do profissional.

\section{OBJETIVOS E METODOLOGIA DA PESQUISA}

"Entendemos pesquisa como um procedimento formal, com método de pensamento reflexivo, que requer um tratamento científico e se constitui no caminho para se conhecer a realidade ou para descobrir verdades parciais.” (LAKATOS et al., 1991, p. 15).

A pesquisa teve por objetivo geral constatar o nível de conhecimento dos alunos especializandos/residentes e sua consciência sobre a interdisciplinaridade no cotidiano do CPA e como objetivos específicos:

- verificar a concepção dos alunos especializandos/ residentes sobre interdisciplinaridade e o processo de aquisição desse conhecimento;

- estudar a interdisciplinaridade no atendimento prestado pelos alunos/ especializandos do CPA;

- identificar o papel do assistente social na equipe interdisciplinar.

A metodologia utilizada para o desenvolvimento da pesquisa foi a exploratória, valendo-se da abordagem quanti-qualitativa, visando aprimorar nossa experiência em torno do assunto pesquisado. Segundo CHIZZOTTI (1995), na abordagem qualitativa todos

\begin{tabular}{llllll}
\hline Serviço Social \& Saúde & Campinas & v. 4 & n. 4 & p. 1-156 & Maio 2005 \\
\hline
\end{tabular}


os fenômenos são igualmente importantes e preciosos; todos os sujeitos são igualmente dignos de estudo todos são iguais, mas permanecem únicos e todos os seus pontos de vista são relevantes. Procura-se compreender a experiência que eles têm e os conceitos que elaboram. O conjunto de dados quantitativos e qualitativos, para MINAYO (1999), se complementam, pois a realidade abrangida por eles interage dinamicamente, excluindo qualquer dicotomia.

Como instrumental técnico para coleta de dados utilizou-se o questionário com perguntas abertas, por este propiciar maior liberdade de expressão aos sujeitos pesquisados.

Para análise dos dados levantados junto aos questionários, foi feita uma interrelação sob uma perspectiva dialética “abarcando o sistema de relações que constrói o modo de conhecimento exterior ao sujeito, mas também as representações sociais que traduzem o mundo dos significados” (MINAYO, 1999, p. 24). Somou-se a isso a teoria, com a prática profissional, uma vez que os profissionais/ especializandos, sujeitos desse estudo, atuaram no mesmo setor da assistente social pesquisadora.

Os resultados obtidos foram apresentados por meio de tabelas com valores em porcentagem e depoimentos, evidenciando o alcance dos objetivos propostos.

O universo da pesquisa foi constituído por alunos especializandos/residentes do curso de especialização iniciado em 2000, com término em fevereiro de 2002 totalizando 13 (100,0\%) profissionais entre as áreas de fonoaudiologia (6), psicologia (3), medicina, otorrinolaringologia (3) e serviço social (1), dentre os quais iniciaram a especialização no ano de 2000 com término em fevereiro de 2002. Os que se dispuseram a participar da pesquisa como sujeitos da amostra foram 09 (69,2\%) garantindo a representatividade das áreas.

\section{ANÁLISE DOS RESULTADOS}

De acordo com os dados levantados nos questionários pode-se caracterizar os sujeitos da pesquisa e verificar seu entendimento sobre a interdisciplinaridade, interrelacionando-o com a teoria pesquisada.

Seu perfil foi traçado por área, abrangendo: gênero, formação, ano de graduação e natureza da universidade. (Gráficos 1, 2 e 3)

\begin{tabular}{llllll}
\hline Serviço Social \& Saúde & Campinas & v. 4 & n. 4 & p. 1-156 & Maio 2005
\end{tabular}


Observamos que $88,9 \%$ dos alunos pesquisados eram mulheres, refletindo a predominância do sexo feminino nos cursos de fonoaudiologia, serviço social e psicologia. O único profissional do sexo masculino era da área de medicina, onde há predominância significativa desse gênero.

A área de fonoaudiologia ficou evidenciada por $44,4 \%$ dos sujeitos, pois abrange um maior número de procedimentos envolvidos nas condutas terapêuticas para diagnóstico, intervenção e (re)habilitação do indivíduo portador de deficiência auditiva.

Gráfico 1 - Perfil dos sujeitos - GÊNERO

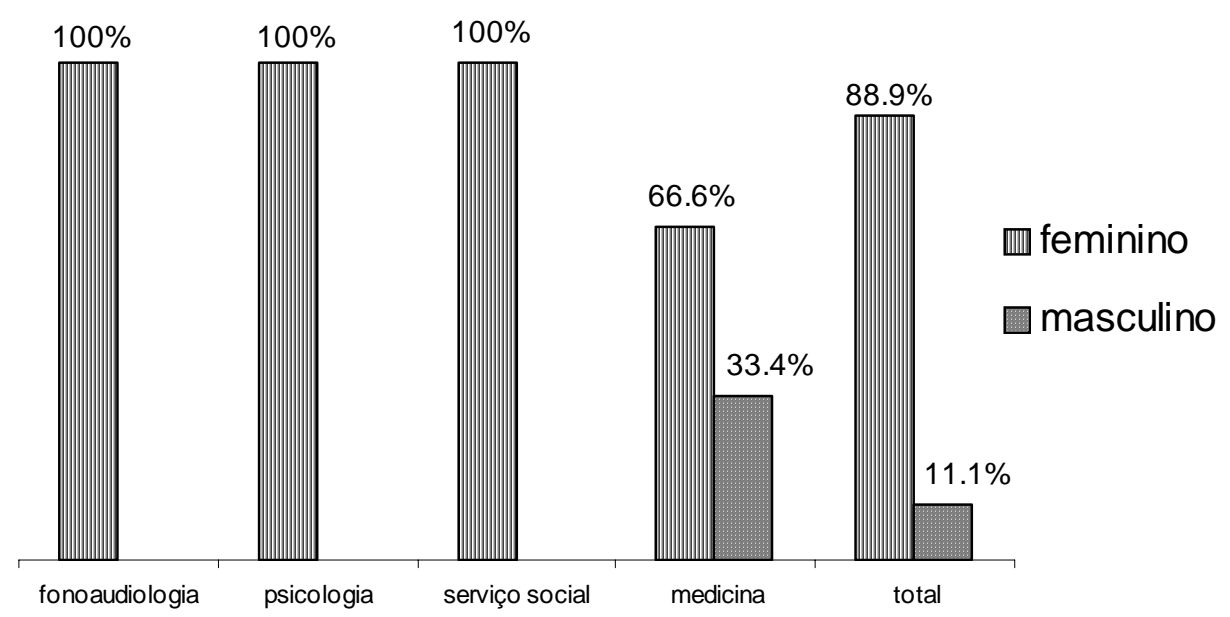




\section{Gráfico 2 - Ano de graduação}

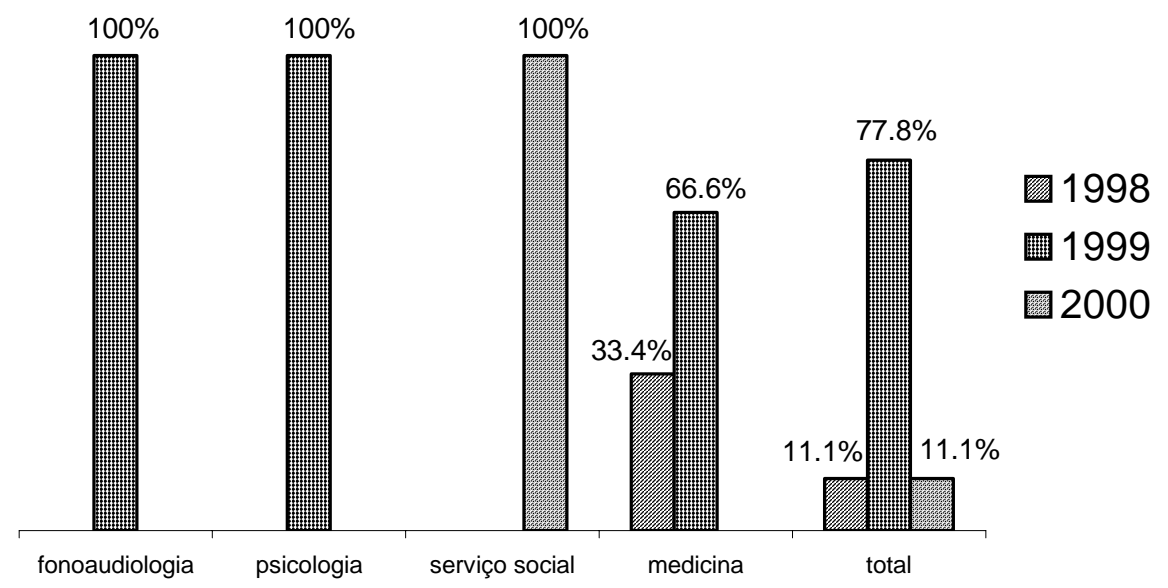

\section{Gráfico 3 - Natureza da instituição formadora}

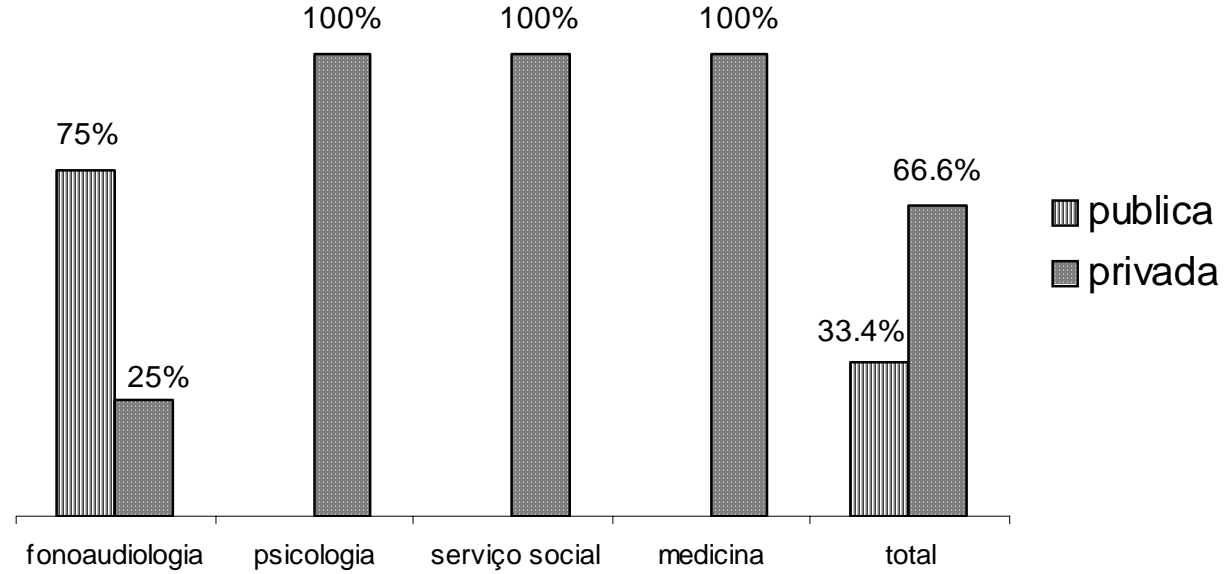

As outras áreas complementam o trabalho realizado pelas fonoaudiólogas, trabalho este, que se dá por meio da interação ${ }^{5}$ das áreas e da interlocução do saber individual de cada profissional.

\footnotetext{
${ }^{5}$ Ação que se exerce mutuamente entre duas ou mais coisas; ou duas ou mais pessoas (FERREIRA, B.H. Minidicionário da Língua Portuguesa. 3 .ed. Rio de Janeiro : Nova Fronteira, 1993 ) 
Constatamos que os profissionais eram formados recentemente e a maioria (77.8\%) graduou-se em 1999 - um dado positivo que revela um comprometimento, com o aprimoramento de sua especialidade e 66.6 \% dos mesmos tiveram acesso ao ensino superior por intermédio de instituição privada. Para esse comprometimento “o aluno precisa ter uma formação que se preocupe com a competência, isto é, a necessidade de conhecer para argumentar o que estava fazendo teórica e praticamente; usando as técnicas não como um instrumento abstrato, mas um instrumento real para o desenvolvimento de sua ação" (ANDRAUS,1996, p. 60-61).

Dentre os profissionais pesquisados, $88,9 \%$ tiveram aulas referentes ao trabalho coletivo, o que reflete a preocupação das escolas de ensino superior, independentemente de sua natureza - pública ou privada - em abordar a questão do trabalho interdisciplinar como um meio efetivo de atender ao paciente em sua totalidade.

Para o conhecimento da interdisciplinaridade, os sujeitos foram questionados a respeito deste tema e as respostas possibilitaram a caracterização exposta no gráfico que se segue.

\section{Gráfico 4 - Entendimento da interdisciplinaridade}

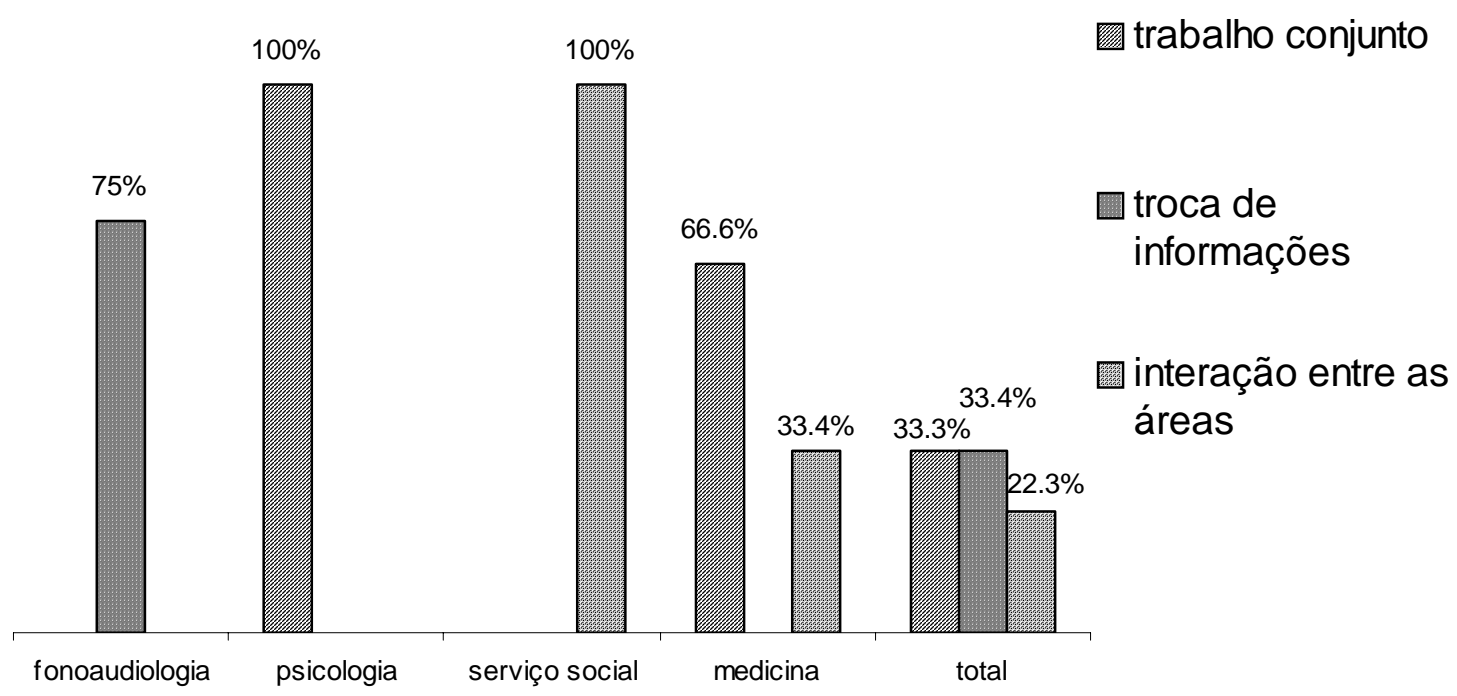

Serviço Social \& Saúde Campinas

v. 4 n. $4 \quad$ p. $1-156$

Maio 2005 
Percebemos que todos os pesquisados tinham entendimento do trabalho interdisciplinar, apesar das diferentes formas de expressá-lo, pois as respostas vieram ao encontro da colocação de SAMPAIO et al. (1989), que destaca a interdisciplinaridade como uma relação de mutualidade, sendo a substituição de uma concepção fragmentária pela unitária do ser humano.

Os profissionais reconhecem que o trabalho, numa perspectiva interdisciplinar, exige união entre as disciplinas e comunicação para efetivação das atividades desenvolvidas. Na tabela acima, 33,3\% dos profissionais entendem a ação interdisciplinar como um trabalho conjunto e 33,4\% consideram-na uma troca de informações. A interdisciplinaridade foi colocada como interação entre as áreas por 22,3\% dos profissionais, entre eles a Assistente Social pesquisadora, que confirma as palavras de RODRIGUES ON (1998, p.157), para quem “o serviço social é uma profissão interdisciplinar por excelência, uma vez que articula diferentes conhecimentos de modo crítico entre prática-teoria e teoria-prática”.

O que se pode dizer é que um trabalho conjunto, com troca de informações e a interação entre as áreas envolvidas, pode efetivar a interdisciplinaridade, principalmente na área da saúde, norteando o foco de atuação não só sobre a deficiência mas sobre o seu portador, em sua totalidade.

Considerando esse entendimento, é importante verificar o momento em que os sujeitos tomaram conhecimento da interdisciplinaridade, uma vez que todos eram graduados, e que $88,8 \%$ dos profissionais tiveram a questão abordada durante a graduação, como mostra o gráfico a seguir. 


\section{Gráfico 5 - Momento em que tomou conhecimento da interdisciplinaridade}

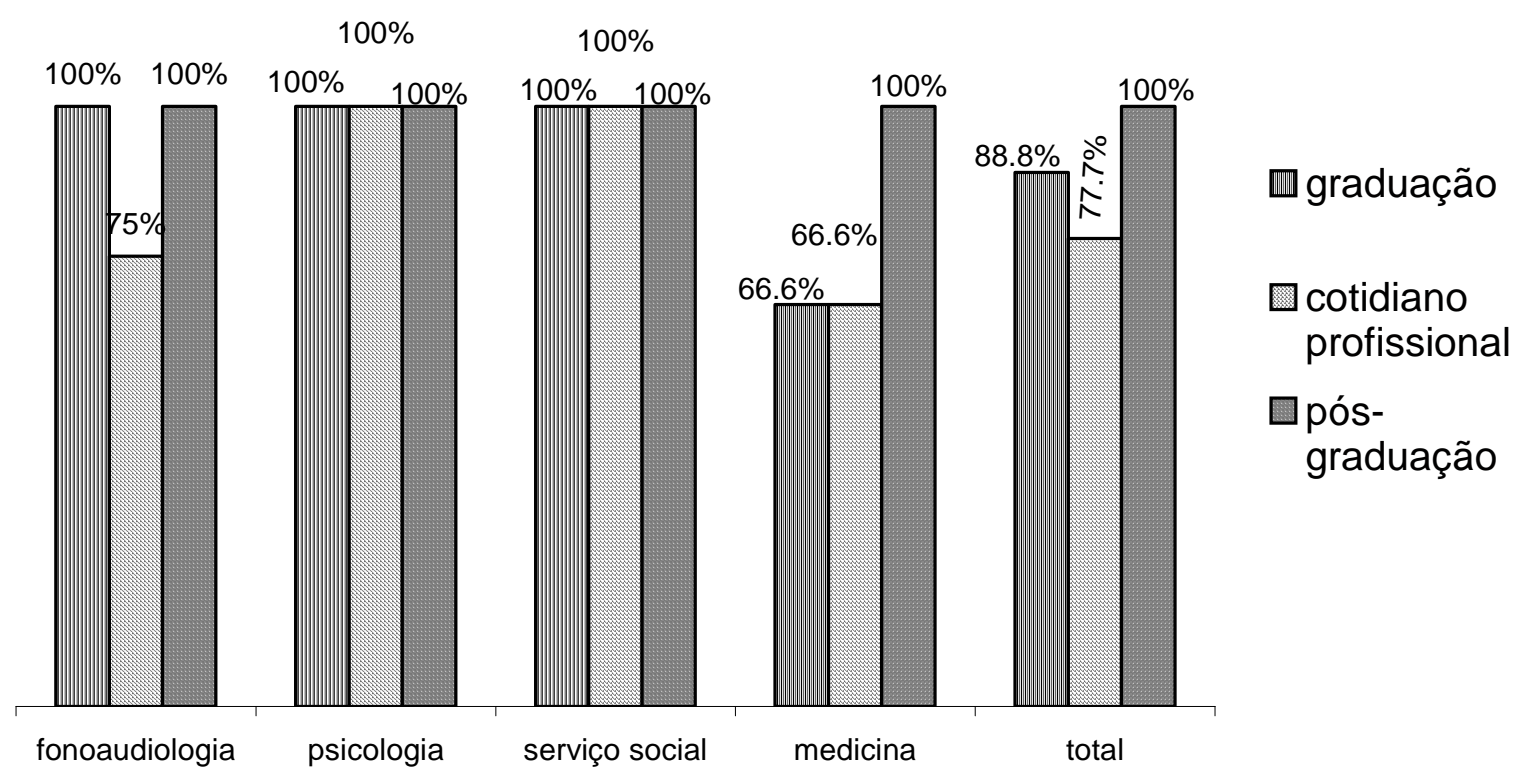

NOTA: A soma ultrapassou 100\% em virtude dos múltiplos momentos em que os sujeitos tiveram contato com o tema.

Apesar de a grande maioria ter tomado conhecimento da interdisciplinaridade antes da pós-graduação (88,8\% na graduação e $77,7 \%$ no cotidiano profissional fora do CPA), a vivência interdisciplinar ficou garantida em 100,0\% dos pesquisados durante o treinamento profissional, o que facilitou a convivência com os profissionais da instituição, melhorou a postura dos mesmos, e os preparou para atuarem fora do CPA. O que se vislumbra é a disseminação ampla da interdisciplinaridade, visto que a maioria dos especializandos/ residentes residem em outras cidades/ regiões.

Somente um profissional da área médica não teve a questão abordada na graduação, fato este superado pela rotina interdisciplinar desenvolvida no cotidiano do CPA. 
Em virtude da ação interdisciplinar ter sido desenvolvida durante o período do estágio no CPA, a próxima questão será a análise da abordagem interdisciplinar nessa unidade.

\section{Gráfico 6 - Como acontece a interdisciplinaridade no CPA}

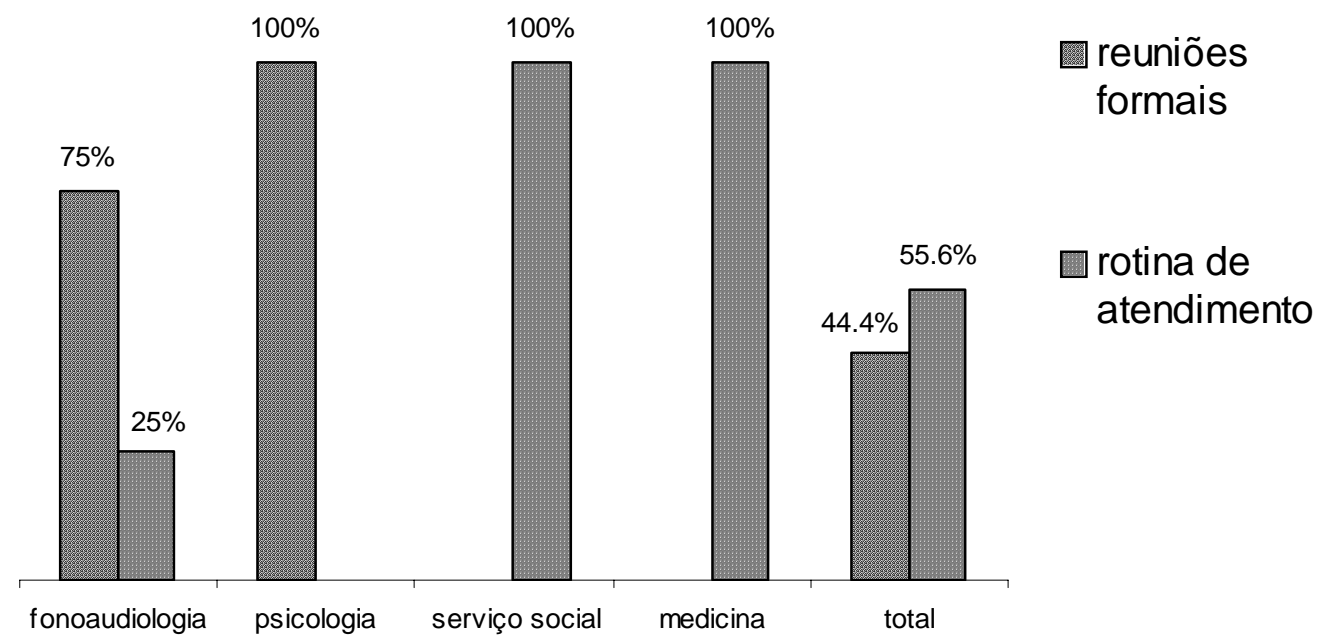

A interdisciplinaridade implica no plano prático-operacional, que se estabeleça mecanismos e estratégias de efetivação do diálogo solidário no trabalho científico (SEVERINO, 1989). Tal afirmação vem ao encontro das respostas contidas na tabela, pois, periodicamente, acontecem reuniões para discussão dos casos atendidos no CPA, com a participação de profissionais de todas as áreas que integram a equipe. Posteriormente a reuniões os profissionais da equipe - supervisores dos alunos /residentes - repassam as informações/ condutas definidas na reunião, como uma forma de "feed-back" dos procedimentos adotados.

É essa dinâmica interdisciplinar das reuniões, dos procedimentos - que envolvem uma troca, uma soma de saberes - que levam o profissional a ver além de sua especialidade, enxergando o paciente como um todo. 
Como pode ser visualisado na tabela, 55, 6\% apontaram as rotinas de atendimento como uma ação interdisciplinar, seguida de 44, 4\% que entenderam que a reunião reflete uma visão conjunta das áreas.

Apesar de não ter sido citado pelos sujeitos da pesquisa, vale ressaltar, ainda, a importância do prontuário que, por ser único, também caracteriza e facilita a interdisciplinaridade nos atendimentos.

Concluindo as questões sobre a interdisciplinaridade, foi solicitado aos sujeitos da pesquisa que traduzissem seu entendimento sobre o tema em apenas uma palavra.

\section{Gráfico 7 - Palavra que traduz a interdisciplinaridade}

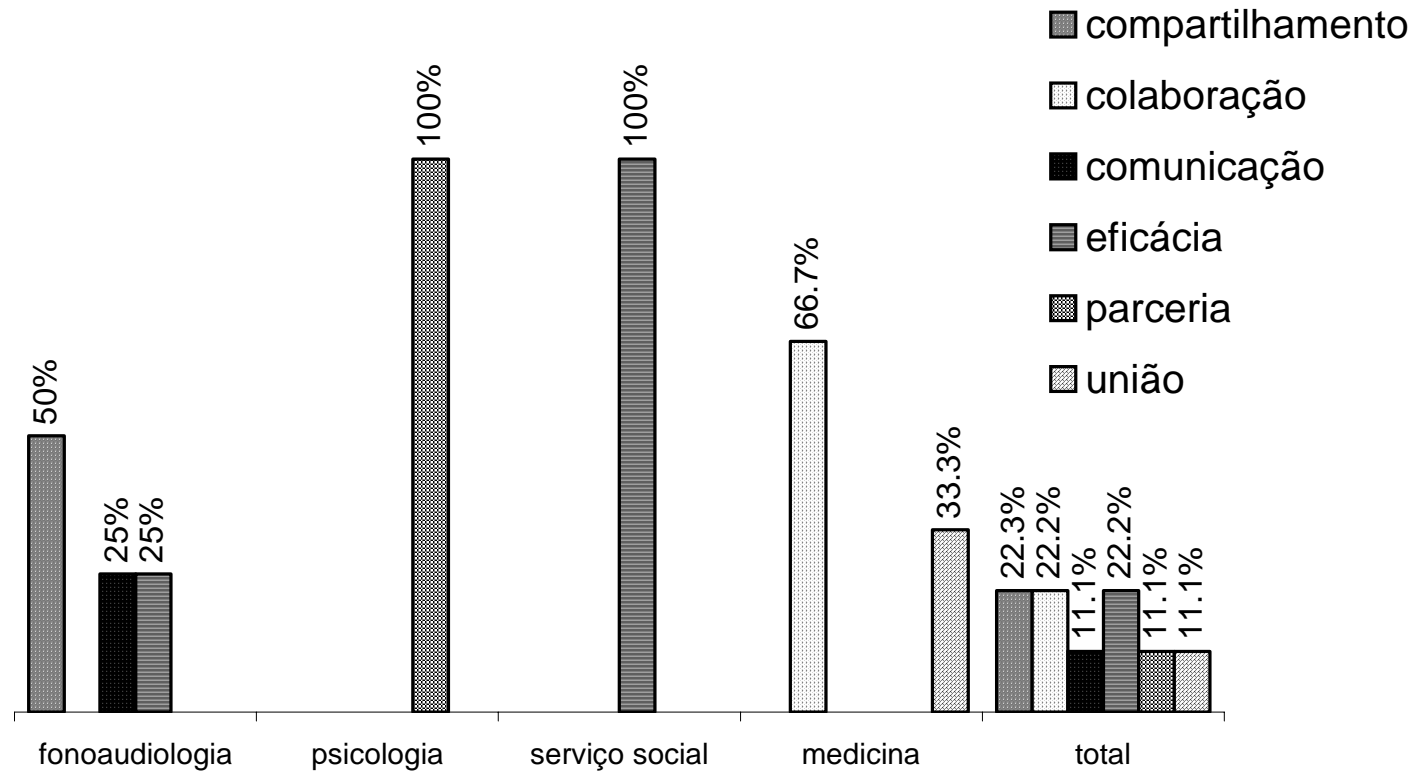

Muitas foram as palavras citadas e, independentemente de seu significado literal, o que se revela é uma interação entre os profissionais e as áreas, extrapolando um simples cumprimento do dever, como cita o autor SAMPAIO et al. (1989 p.82): “A interdisciplinaridade consiste num trabalho em comum, onde se consideram a interação das disciplinas científicas, de seus conceitos, diretrizes, de sua metodologia e de seus procedimentos". 
Dentre os sujeitos pesquisados, 22,3\% traduziram interdisciplinaridade como compartilhar, seguida das palavras colaboração e eficácia, citadas por 22,2\% dos alunos/especializandos.

As palavras compartilhar, colaboração, parceria e união têm o mesmo significado e foram citadas pelos demais, revelando uma unidade de pensamento sobre a interdisciplinaridade. Ser interdisciplinar é compartilhar o saber unitário complementado por novos conhecimentos junto à equipe que desenvolve uma atividade.

Como o serviço social é considerado uma profissão interdisciplinar por excelência, de acordo com RODRIGUES ON (1998), questionamos os sujeitos da pesquisa sobre o trabalho do Assistente Social na equipe interdisciplinar do CPA.

\section{Gráfico 8 - O papel do Assistente Social na equipe interdisciplinar}

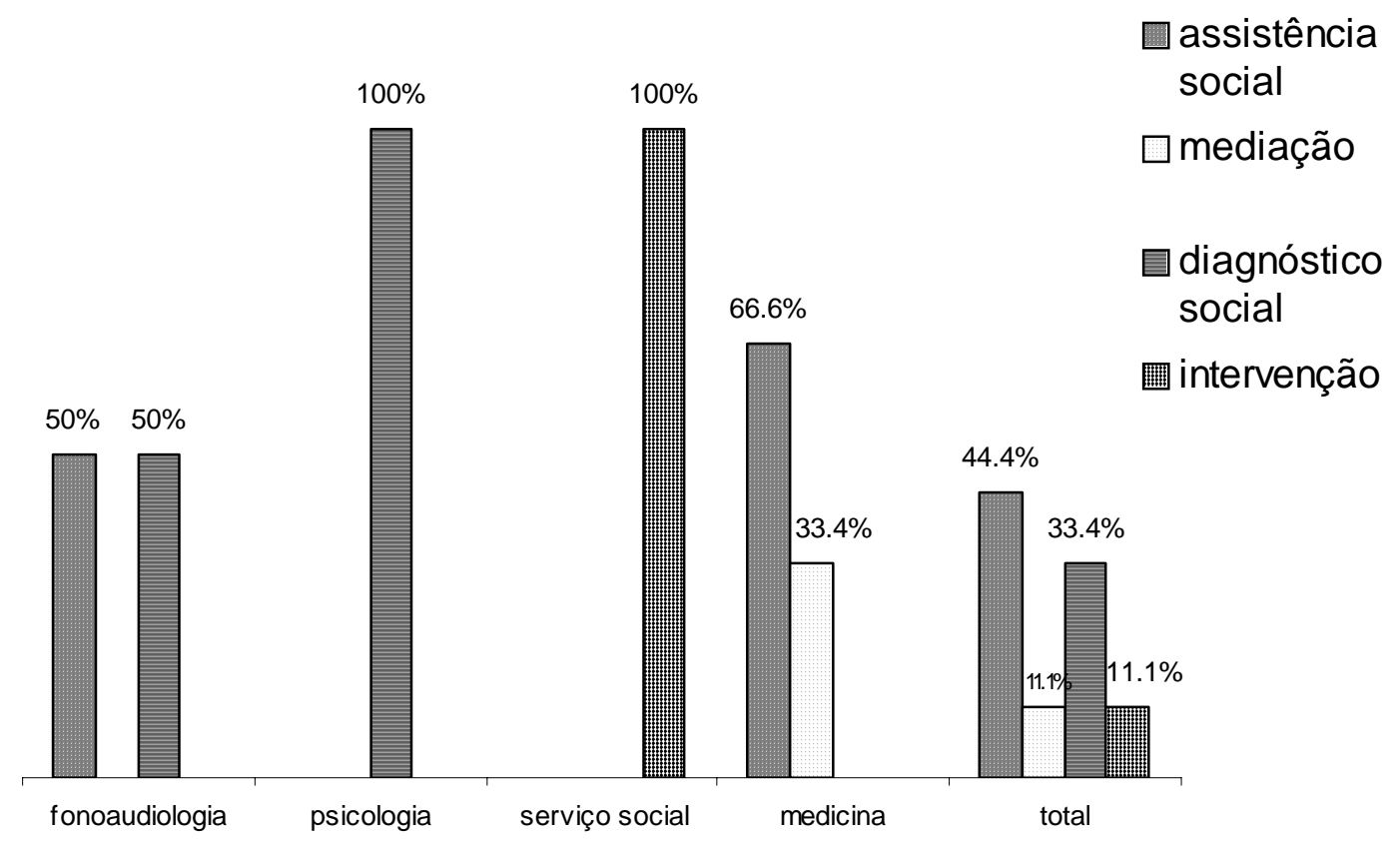

Dentre os pesquisados, 44, 4\% dos sujeitos citaram o Assistente Social como prestador de assistência social, encarada, aqui, como atendimento das necessidades imediatas - encaminhamentos a recursos para estada, alimentação e outros. No entanto, é 
de conhecimento de todos da equipe que esses encaminhamentos acontecem após diagnóstico social do profissional.

Esse procedimento - diagnóstico social - foi reconhecido por 33, 4\% dos sujeitos como sendo o papel do Assistente Social na equipe, como bem expõe GRACIANO (1996): o serviço social fornece à equipe interdisciplinar uma visão da realidade sócio-econômica e cultural dos pacientes, por meio de um diagnóstico das suas condições de vida, pois além de instrumentalizar a ação profissional do Assistente Social, permite colaborar com a equipe no plano de tratamento com base na realidade social de cada indivíduo.

O papel do Assistente Social citado pelos demais 22,2\% dos sujeitos, foi de intervenção $(11,1 \%)$ e mediação $(11,1 \%)$, confirmando os dizeres de LOURENÇÃO (1998), em sua pesquisa no HRAC/USP sobre o papel do Assistente Social na equipe interdisciplinar: quanto ao papel do Assistente Social na equipe interdisciplinar, observamos que o profissional desta área, atua numa perspectiva de totalidade, trabalhando na mediação entre paciente/família e equipe como também entre as diversas áreas do setor em que está inserido, pois em sua atuação o profissional, realiza seu trabalho de forma a atender as necessidades apresentadas por seus usuários, levando os mesmos buscarem seus direitos enquanto cidadãos.

A interdisciplinaridade é algo que vivemos profissionalmente, pois para que a mesma ocorra é necessária a participação de indivíduos com o mesmo objetivo, voltados para um enfrentamento conjunto do problema apresentado. No trabalho grupal, o saber individual não é anulado diante dos diferentes saberes. Mas compartilhado, reconstruído e ampliado.

Como último item do questionário, foi solicitado que os sujeitos fizessem comentários, alguns que serão transcritos para ilustrar a postura dos sujeitos pesquisados diante do contexto em que atuam.

"É muito importante as pessoas estarem cientes da interdisciplinaridade, compartilhando informações. " ( fonoaudiológa )

\begin{tabular}{llllll}
\hline Serviço Social \& Saúde & Campinas & v. 4 & n. 4 & p. 1-156 & Maio 2005
\end{tabular} 
“A dinâmica interdisciplinar tem suas dificuldades para acontecer, em relação à tempo, e postura profissional, mas sua essência de trabalho, nos dias atuais, é importantíssima.” (psicóloga)

“Não é apenas importante a comunicação, mas sim darmos valor ao que o outro está sugerindo e trabalharmos a partir disso.” (fonoaudióloga)

“Acho um trabalho válido (o interdisciplinar), pois apesar de ser muito falado em equipe interdisciplinar, a vaidade, cobiça, inveja ainda não nos permitem viver... literalmente em equipe.” (otorrinolaringologista)

"Todo aluno, durante a graduação, deveria ter uma matéria específica relacionada ao trabalho interdisciplinar, o que permitiria ao profissional uma visão de totalidade do sujeito, para garantir a eficácia de sua ação” (assistente social)

Os depoimentos enfatizaram o valor do trabalho interdisciplinar $\mathrm{e}$ as dificuldades apresentadas pelo mesmo. Os profissionais destacaram o trabalho em equipe como uma atividade que envolve o compartilhamento de informações, uma comunicação efetiva entre os membros da equipe, o que viabiliza a comunhão entre os mesmos, garantindo a eficácia dos trabalhos desenvolvidos.

Abordou-se, também, a questão da individualidade, já que esta é uma das dificuldades de se colocar a interdisciplinaridade em prática; tal atitude dificulta a ação profissional e pode, muitas vezes torná-la ineficiente.

\section{CONSIDERAÇÕES FINAIS}

O exercício da interdisciplinaridade não é algo pronto e acabado. Ela - a interdisciplinaridade - é delineada pelas exigências das situações que se apresentam. Em cada equipe acontece de diversas formas.

Os sujeitos da pesquisa foram alunos/especializandos graduados recentemente, em média há 3 anos, representados pelo gênero feminino ( 88,9\% ), e evidenciados por $44,4 \%$ de graduados em fonoaudiologia, dos quais 66,6\% freqüentaram instituição de ensino de natureza privada, o que retrata a realidade de uma sociedade capitalista que \begin{tabular}{llllll}
\hline Serviço Social \& Saúde & Campinas & v. 4 & n. 4 & p. 1-156 & Maio 2005
\end{tabular} 
privilegia o privado em detrimento do público. Os profissionais buscaram a pós-graduação para o aprimoramento de sua área, o que revela o comprometimento dos mesmos com a extensão da formação acadêmica, incentivados pelas instituições que atuam concomitantemente à prestação de serviços, desenvolvendo um trabalho voltado para o ensino e pesquisa.

Constatamos, com a presente pesquisa, que os especializandos/ residentes, apesar das diferentes formas de se expressarem, têm conhecimento do trabalho interdisciplinar e da sua importância para a eficácia das atividades desenvolvidas. A ação interdisciplinar foi identificada como um trabalho em conjunto e troca de informações (33,3\% cada).

Dos pesquisados, $88,8 \%$ tiveram a questão do trabalho interdisciplinar abordada durante a graduação, o que contribuiu para a atuação dos mesmos junto à equipe do CPA. Observamos, ainda, que o profissional que não teve contato com o tema durante a graduação superou tal falta no período de especialização, no CPA do HRAC/USP, que atua dentro de uma filosofia interdisciplinar. Tal postura foi reconhecida por 100,0\% dos sujeitos, no momento em que citaram a pós-graduação como oportunidade de vivência da interdisciplinaridade.

Os especializandos, apesar de desenvolverem diferentes atividades no CPA, relataram que a interdisciplinaridade presente nas rotinas de atendimento é efetivada nas reuniões de equipe para discussão formal dos casos.

Dentro dessa perspectiva, os mesmos traduziram a interdisciplinaridade como compartilhamento (22,3\%), colaboração (22,2\%) e eficácia (22,2\%), demonstrando, assim, terem assimilado o verdadeiro sentido vivenciado no treinamento profissional.

Na equipe interdisciplinar, o trabalho do Assistente Social foi reconhecido como dirigido para assistência social, diagnóstico social - que possibilita aos demais se interarem da realidade do paciente - intervenção, mediação, ratificando resultados de outros estudos desenvolvidos na área de Serviço Social.

Os comentários sugeriram a disposição/ preocupação dos profissionais para uma vivência interdisciplinar, principalmente a partir do seu treinamento.

A pesquisadora, também sujeito da pesquisa, surpreendeu-se com os profissionais da área de medicina, pois além de seu compromisso em responder os 
questionários (100,0\% o fizeram), desmistificaram a visão que a mesma tinha quanto aos profissionais desta área, que era a de pessoas que se consideravam auto-suficientes. O contrário foi constatado, pois se revelaram pessoas comprometidas com os pacientes e com a equipe.

Diante das respostas e considerações, o que se constatou é que o treinamento profissional no CPA oportunizou aos alunos/ residentes uma vivência efetivamente interdisciplinar, preparando-os para o enfrentamento da realidade que se apresenta, principalmente nos serviços de saúde, tão fragilizados e carentes de profissionais comprometidos com os usuários desse serviço.

\section{ABSTRACT}

The Centro de Pesquisas Audiológicas - CPA - (Center of Audiologycal Research) is one of the units of the Hospital de Anomalias Craniofaciais - HRAC - from University of São Paulo, which assists people with hearing disorders. Its work is addressed to teaching, research and services rendering. It develops programs that demand an interdisciplinary team and in all areas there are professionals having a post-graduation, in trainning. Due the interdisciplinarary assistance rendered by CPA - according to the HRAC philosophy - it was realized the necessity of investigating the professional's knowlegde about this theme: interdisciplinarity.The research was exploratory using the quali-quantitativy approach and as a tecnichal tool, the questionnaire, with opened questions .The universe of this research was 13 professionals $(100,0 \%)$ in trainning, from the different areas, represented by 9 $(69,2 \%)$ subjects and had as goal to check their level of kowlegde and their consciense about the interdisciplinarity in the daily activities at CPA.. Basically, it was showed up that all the professionals recognized the work developed by CPA as an interdisciplinary one and, besides $88,9 \%$ of them had got known about interdisciplinarity in the graduation time, the real interdisciplinary experience by $100,0 \%$ was got just during their professional trainning.

KEYWORDS : Patient Care Team, Social Work.

\begin{tabular}{llllll}
\hline Serviço Social \& Saúde & Campinas & v. 4 & n. 4 & p. 1-156 & Maio 2005
\end{tabular} 


\section{REFERÊNCIAS BIBLIOGRÁFICAS}

ANDRAUS, R. C. Olhando para o serviço social numa perspectiva interdisciplinar. Bauru: EDUSC, 1996. 132 p.

CARRARA, K. Educação, universidade e pesquisa. Marília: FAPESP, 2001. 250 p.

DEMO, P. Conhecimento moderno: sobre ética e intervenção do conhecimento. Petrópolis-RJ: Vozes, 1997. 125 p.

CHIZZOTTI, A. Pesquisa em ciências humanas e sociais. 2. ed. São Paulo: Cortez, 1995. $164 \mathrm{p}$.

FAZENDA, I. C. A. Práticas interdisciplinares na escola. 7. ed. São Paulo: Cortez, 2001. $127 \mathrm{p}$.

GARCIA, R. C. M. O curso de especialização em serviço social na área da saúde e reabilitação do HRAC - USP: a questão da formação e colocação profissional. 2001. 30f. Monografia (Especialização em serviço social na área da saúde e reabilitação) - Hospital de Reabilitação e Anomalias Craniofaciais, Universidade de São Paulo, Bauru.

GRACIANO, M. I. G. Construindo espaços: a história das associações de pais e portadores de lesões lábio-palatais e a contribuição do serviço social. 1996. 328 p. Tese (Doutorado em Serviço Social) - Pontifícia Universidade Católica de São Paulo, São Paulo. LAKATOS, E. M.; MARCONI, M. de A. Metodologia científica. 2. ed. São Paulo: Atlas, 1991. 249 p.

LOURENÇÃO,C. M. Avaliação da importância do estudo sócio-econômico familiar para o planejamento e intervenção da equipe interdisciplinar do Hospital de Reabilitação de Anomalias Craniofaciais (HRAC/USP). 1998. 139f. Monografia (Especialização em serviço social na área da saúde e reabilitação) - Hospital de Reabilitação e Anomalias Craniofaciais, Universidade de São Paulo, Bauru.

MINAYO, M. C. S. Pesquisa social: teoria, método e criatividade. Petrópolis: Vozes, 1999. $80 \mathrm{p}$.

ROBBINS, H.; FINLEY, M. Por que as equipes não funcionam: o que não deu certo e como torná-las criativas e eficientes. Rio de Janeiro: Campus, 1997. 253 p. 
RORIGUES ON, M. L. R. O serviço social e a perspectiva interdisciplinar. In: MARTINELLI, M. L. et al (org.) $O$ uno e o múltiplo nas relações do saber. São Paulo: Cortez, 1998. p. 153--157.

SAMPAIO, C. C. et al. Interdisciplinaridade em questão: análise de uma política de saúde voltada à mulher. In: SÁ, J. L. M. (org.). Serviço social e interdisciplinaridade: dos fundamentos filosóficos à prática interdisciplinar no ensino, pesquisa e extensão. São Paulo: Cortez, 1989. p. 77-95.

SEVERINO, A. J. Subsídios para uma reflexão sobre novos caminhos da interdisciplinaridade. In: SÁ, J. L. M. (org.) Serviço social e interdisciplinaridade: dos fundamentos filosóficos à prática interdisciplinar no ensino, pesquisa e extensão. São Paulo: Cortez, 1989. p. 11-21. 